\title{
The Issue of Holistic Development of Young Children in ECE Centres of Botswana
}

\author{
Kabita Bose \\ Department of Primary Education, University of Botswana, Botswana
}

\begin{abstract}
A study on the status of Early Childhood Care and Education (ECC and E) in Botswana established an absence of a prescribed curriculum and a very low rate of formal training of the Early Childhood Education (ECE) teachers [4]. Thus, under the existing circumstances, it was necessary to find out the alternative training measures that were made available to the practicing ECE teachers and the existing classroom practices. This part of the study mapped the views of the teachers working in ECE centres, as demonstrated by their in-service training, classroom practices and. The study comprised of 39 teachers from 39 ECE centres in the neighbourhood. Their views were obtained from a semi-structured questionnaire. A quantitative approach was used for analysis of the data. The study found that around $60 \%$ of the in-service teachers attended ECE workshops as alternative training measures. However, it emerged from the study that the content of the workshops needed to be enriched. It also revealed that only $54 \%$ of teachers promoted holistic development that catered to physical, cognitive, emotional as well as social domains at tandem; and remaining promoted only a combination of some of the developmental aspects, neglecting some crucial ones completely at times. The findings also indicated that greater emphasis was laid on the development of physical aspect as compared to the other domains.
\end{abstract}

\section{Introduction}

Early Childhood Education (ECE) deals with young children aged 0-8 years and their overall development that takes into account of their educational, health, psychological, philosophical, cultural, historical and sociological domains. Young children at this age are vulnerable and need proper care and education for an appropriate stimulation and learning. During this period, children develop very fast, use all their senses and as a result the potential gains are tremendous. At this stage, an appropriate stimulation is necessary that can improve their motor skills, critical thinking, problem solving, enhanced mathematical thinking, increased creativity, higher level of language development and motivation [14]. And to provide that, one needs trained teachers who could stimulate young children to learn and benefit maximum from all that is available. At the same time, there is a need to introduce a well planned ECE curriculum that could cater to development of physical, cognitive, social and emotional aspects, leading to an overall development of young children. However, review of literature regarding availability of trained ECE teachers as well as development of ECE curriculum reveals a mixed response. Some studies show that for most early childhood care and education programs, teachers do not attain a bachelor's degree, and the majority of the states do not have teachers in ECE centres that undergo any pre-service training; much less have a BA in early childhood education. It also shows that only about half of the teachers in private ECE settings or Head Start centres are with a BA or an Associate Degree. And therefore, most ECE programs are disqualified as mediocre [1]. Another study emphasised that high qualification of staff is associated with high quality of ECE service delivery, and found that usually higher quality programs tend to employ teachers who are more qualified [20]. Thus, the ECE teachers, who would in turn, provide quality care and education; need a formal professional advancement that could empower them with ECE related knowledge and skills.

As regards ECE curriculum, a few other studies revealed that usage of government prescribed curriculum is prevalent mainly in developed countries like England, to ensure quality and cultural appropriateness. Whereas some others start without operational guidelines initially; and procure a national curriculum subsequently. A study found that both Sweden and Norway developed guidelines and annual plan of the institutional activities of preschools to start with, and implemented the general guidelines effectively in order to assist the preschool practitioners. Whereas, they developed a curriculum which outlined goals, content, methods and evaluation and emphasised subject areas (society religion and ethics, physical activity and health, aesthetic subjects, language, literacy and communication as well as nature technology and environment) that were to be experienced by learners each subsequent year, along with activities 
such as play, creativity, joy and humour [2]. Thus, it is quite clear that to run quality ECE centres in any country, it is necessary to have a combination of both ECE trained teachers as well as prescribed ECE curriculum.

However, Botswana, which is a developing country, has a very different scenario. A study funded by the office of Research and Development (ORD) of University of Botswana (UB) found that although the Ministry of Education (MOE) was made responsible for coordinating early childhood services and training of ECE teachers, and establishing a minimum curriculum framework for day-care and pre-primary services, really nothing much could be established due to various constraints. It also revealed that there was no dearth of variety of ECE centres in the country that were running with various types of ECE programmes. It also revealed that nearly half of those ECE centres were run by private sector alone and the remaining was run by different types of organizations like Non Governmental, or faith based types. The same study also found that nearly $18 \%$ of ECE centres had no trained teachers at all in their premises. It further elaborated that out of the total number of ECE teachers (174) that were recruited; nearly 50\% (85) of the teachers were not trained in ECE at all! And on top of that, it added that none of those centres had a prescribed curriculum that could provide some guidelines along with activities to the teachers. Thus, it could well be predicted that this absence of a prescribed ECE curriculum could have led to a situation where the teachers could not provide young children with proper guidance, care and education! Because it is well understood that a prescribed ECE curriculum should be able to guide teachers; both trained as well as untrained ones, in their deliberations and ensure that the activities that are practised in the classrooms are developmentally appropriate for the children [4]. This state of affairs regarding ECE is alarming. Any ECE programme that a young child is exposed to, should be such that it can leave a mark at the most impressionable age! And that cannot be possible without Trained ECE teachers as well as prescribed ECE curriculum!

However, it is worth mentioning here that the literature regarding ECE curriculum in Botswana also indicated that a blue print of the ECE National Curriculum for pre-primary sector was being developed, both for piloting and implementing to the pre-schools; and some teacher training was also being planned that was to be implemented during the National Development tenure of 2003-2009 [18].

But looking at the existing situation in Botswana, one often questions the quality of ECE programmes! The question that often bothers is what is being done to ensure quality pre-school education that could meet both the individual as well as cultural needs of young children? Thus, the author of this paper felt the need to find out what exactly was happening within the classrooms of the ECE centres, in the absence of both prescribed ECE curriculum as well as ECE trained teachers. It also became necessary to determine the measures that were taken to curb such a worrisome situation. Hence, this study was conducted which mapped the views of the ECE teachers as demonstrated by their practices and involvement in the classrooms, as well as the training facilities that were made available to them, to upgrade their current, helpless situation.

\section{Objectives of the study}

Objectives of the study were to find out the:

1. Alternative training measures that were provided to ECE teachers

2. Adoption of any ECE curriculum in the absence of a national prescribed curriculum

3. Promotion of a holistic development in ECE classrooms

\section{Methodology}

A methodology is comprised of a set of methods and principles used to carry out research and it provides a better understanding of how the project was conducted and the data collection techniques that were employed to provide answers to the research objectives. A survey research design was employed for the study. The population of a study is the group of interest to which the result of the study would ideally be generalized [10]. Due to the highest concentration of varied types of ECE programs (20\%) in the whole country and cost effectiveness as well as proximity, Gaborone and its surrounding areas like Tlokweng and Phakalane were selected as population of the research study. A purposive sampling technique was used because of their typical characteristics relative to the phenomenon under study, in this case both region and the available teachers, rather than selecting them at random [21]. Out of a total of 82, 40 i.e., $50 \%$ of ECE were selected by keeping in mind that different types of ECE programmes that existed in the specified area should be retained. This was done to provide a fair representation of ECE centres in the specified area. However, one institutional centre which was operating solely with the help of student teachers, did not feel proper to participate in the study. And as a result, the sample comprised of thirty nine (39) teachers only. Taking cues from Gay and Airasian [10] the most appropriate instrument to use was a questionnaire and not a detailed interview as that was the best option on the ground at that moment. The questionnaire consisted of both closed and open-ended items and was piloted in a nearby ECE centre that was included in the current sample, to test its validity and reliability. A quantitative approach was employed to analyse the data and retrieve relevant information. The data collected was 
cleaned, coded and entered by using SPSS (Statistical Package for Social Sciences) and presented in the form of tables and graphs wherever possible.

\section{Results and Discussions}

The findings of the study are presented in the following section under subheadings as follows:

\subsection{Demographic Information}

In the study, entire population of teachers comprised of females only (Figure 1). It is a fact that child care facilities are still populated by females. This perhaps indicates that more males need to be attracted into the field of child care to act as role models and father figures for children who come from single parent families and also because children need to know that there are men who are caring and loving [8]. Around 66\% (26) of the teachers of the sample were still in their youth (below 40 years) and only 8\% (3) teachers were mature and elderly (over 50 years old). This is quite optimistic and thus one would expect them to be energetic and active to take care of young children in classroom settings.

In general, a good percentage of the participants had formal training, not necessarily in ECE. Around $41 \%$ (16) teachers had acquired diploma, 46\% (18) had acquired certificate and only $5 \%$ (2) had acquired degree qualifications. Whereas, $7.5 \%$ (3) had no higher qualifications at all, and had attained only 2 to 3 years of secondary education (Figure 1).

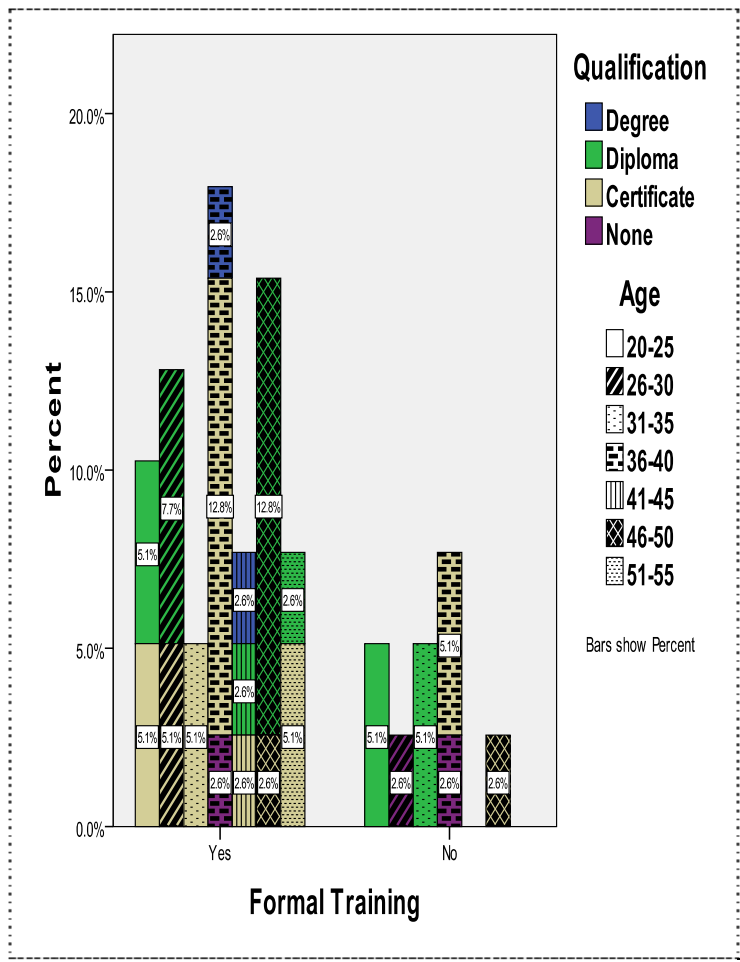

Figure1. Demographic data
It was also found, that $77 \%$ (30) of the selected sample were ECE trained primarily from Botswana (Figure 1). Some were trained in overseas like Zimbabwe, Zambia, South Africa, South Korea, Kenya and Sri Lanka. And the remaining 23\% of the sample was not trained in ECE at all. At this juncture, it is worth mentioning that another part of the study revealed that out of the total number of teachers that were recruited in these 39 ECE centres, almost $50 \%$ of the teachers were not trained in ECE! Perhaps, the adoption of a purposive sampling technique in selection of sample prohibited the untrained teachers from taking part in the current study!

This scarcity of trained teachers in any discipline is a universal truth. There are worldwide constraints of being an adult learner. Lack of adequate training centres, academic insecurity, language barriers and inability to pay for course work are constraints encountered by early care and education teachers in trying to improve their qualification and capacity, so as to help create a knowledgeable and qualified workforce [1].

Botswana has the same scenario as well. Currently there is only one training centre which produces only 30 teachers per year at a certificate level for the whole country [17]. This falls short of satisfying the demand for teachers. Thus it is necessary to make some alternative provisions available to the existing untrained teachers, so that they can upgrade their knowledge and deliver the best to the most promising young children of ECE centres in the country.

Studies of Australian early childhood centres on traditional perspectives of professional development through a re-conceptualization of early childhood growth proposed alternative perspectives, which could recognize staff as empowered learners capable of building working knowledge through engagement in different aspects of EC practice over time. This engagement referred to activities such as workshop and conference presentations, participant observation and data gathering at shared planning meetings, which could allow staff members with minimal qualifications, but with insight and commitment necessary for a professional growth, to share with others and promote a move from being "non professional" to being "professional" [9]. In Botswana as well such alternative measures needs to be provided. Hence, the participants of the current study were asked about the alternative training facilities that were provided to them as in-service teachers.

\subsection{Alternate Training Facilities Provided}

The study revealed that (Figure 2) only 60\% of the teachers had attended ECE workshops which covered relevant working knowledge through engagement in different aspects of ECE practice 
over time. And around $40 \%$ of the ECE teachers were continuing as it is, perhaps without any formal training in the first place; and without any subsequent training in ECE during their in-service tenure. It also revealed that only $22.5 \%$ attended Early Childhood content, and another 20\% went through Teaching Methods content. Rest of them attended content related to nutrition, writing skills, work planning and cleanliness, without covering the basic topics on ECE and methodology, though each of these topics is also very important in its own standing.

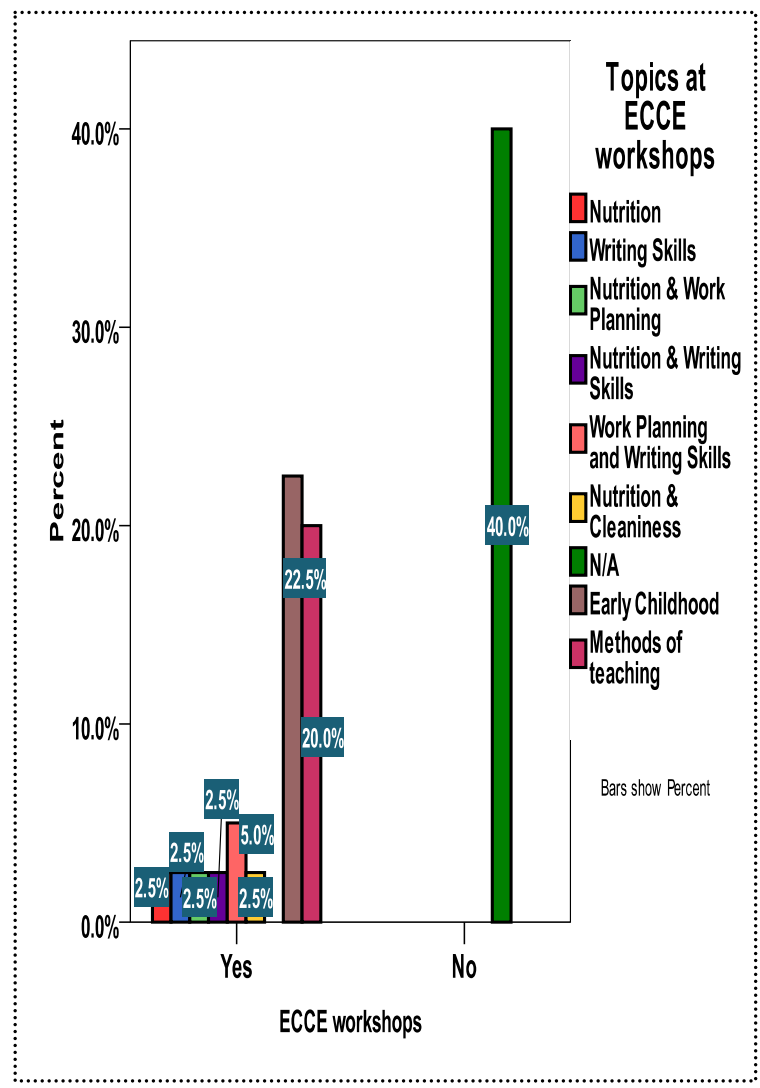

Figure 2.Workshops Attended

Next part of the study dealt with the questions regarding adoption of any ECE curriculum in the absence of a prescribed one. This was necessary in order to understand what was being done to provide rich stimulation to young children.

\subsection{Adoption of ECC and E Curriculum}

Literature revealed that the MOE in Botswana was bestowed with a responsibility of prescribing a standard ECE curriculum that would facilitate the overall development of young children [17]. However, that could not be made available. The results revealed that around $50 \%$ of ECE centres, who did not have any curriculum, used alternatives like adopting either a South African Curriculum or a combination of curriculum prescribed by other countries (Figure 3) [5]. This led to a heavy dependency on curriculum other than its own, and perhaps was not culturally appropriate at all for the children who are growing up in Botswana!

On the other hand, the findings showed that as large as $38.5 \%$ of the ECE centres, who did not have any prescribed curriculum, did not bother to borrow any curriculum and as a result did whatever suited them the best. In addition, another 10.3\% used self-made curriculum based on different themes or Montessori Method (Figure 3). This is alarming, as the picture clearly shows that almost $50 \%$ of them depended on their own knowledge and experience and another $50 \%$ depended on curriculum meant for children of other countries. It is even more disturbing as we saw earlier that almost about 50\% of the teachers who were working in ECE centres were untrained. Thus what must be happening when the untrained teachers decide to develop their own curriculum for the young ones! And one wonders whether one can sit peacefully depending on the curriculum improvised by such untrained teachers?

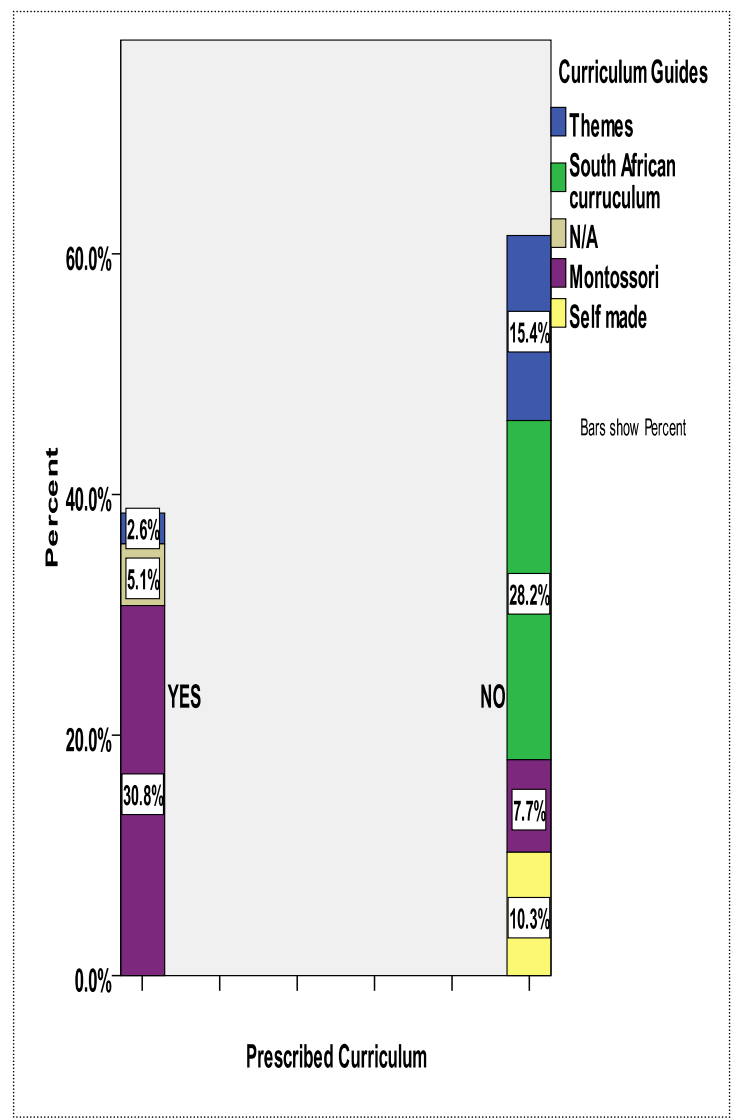

Figure 3. ECE Curriculum and Alternatives

Next pertinent questions thus, were what exactly were happening in ECE classrooms? And in order to find that out it became necessary to probe further, regarding the developmental aspects that were being promoted, the activities that were organised, and the materials that were used in the in the ECE classrooms! It also became necessary to find out the measures that were taken by the ECE teachers to provide a holistic development to the 
young children. Because the introduction of an appropriate curriculum that caters to an overall development of young children is necessary for any ECE centre to achieve the desired outcome, i.e. nothing but a quality ECE programme!

\subsection{Promotion of Developmental Aspects}

The study also revealed that only about half of the respondents (54\%) promoted holistic development that catered to all the aspects namely the physical, cognitive, emotional and social ones at tandem (Figure 4). The remaining, however, promoted only a combination of a few developmental aspects, neglecting some of the crucial ones completely at times that dealt either with cognitive, or physical, or social, or emotional aspects.

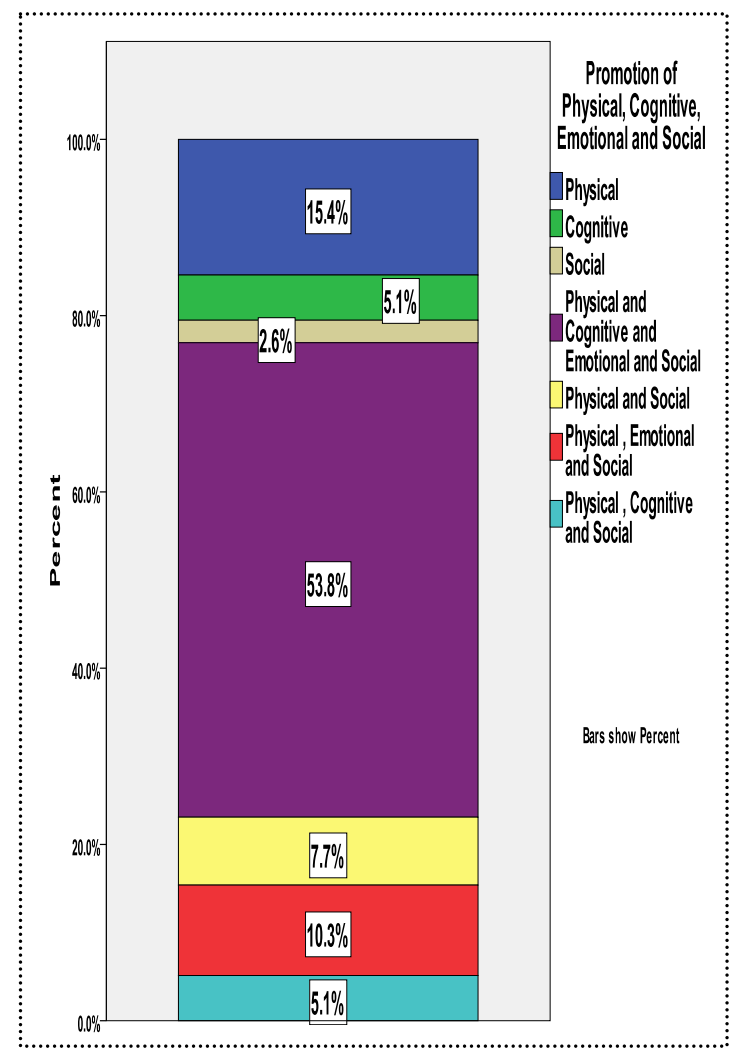

Figure 4. Promotion of Holistic Development

\subsection{Activities Organised In the ECE Classrooms}

It is worth mentioning here that almost all of them organised activities related to games, building blocks, gymnastics and activities requiring eye-hand coordination. This, no doubt, emphasised physical development. Colouring, art and music, free expressions were also given a lot of importance leading to physical, social and emotional development. Whereas, less than half of them
(46\%) attempted arithmetic and pre-writing activities (Figure 5) that automatically catered to cognitive development and finer motor coordination. In other words the ECE teachers were heavily inclined to use activities in the classrooms that would enhance physical domain primarily.

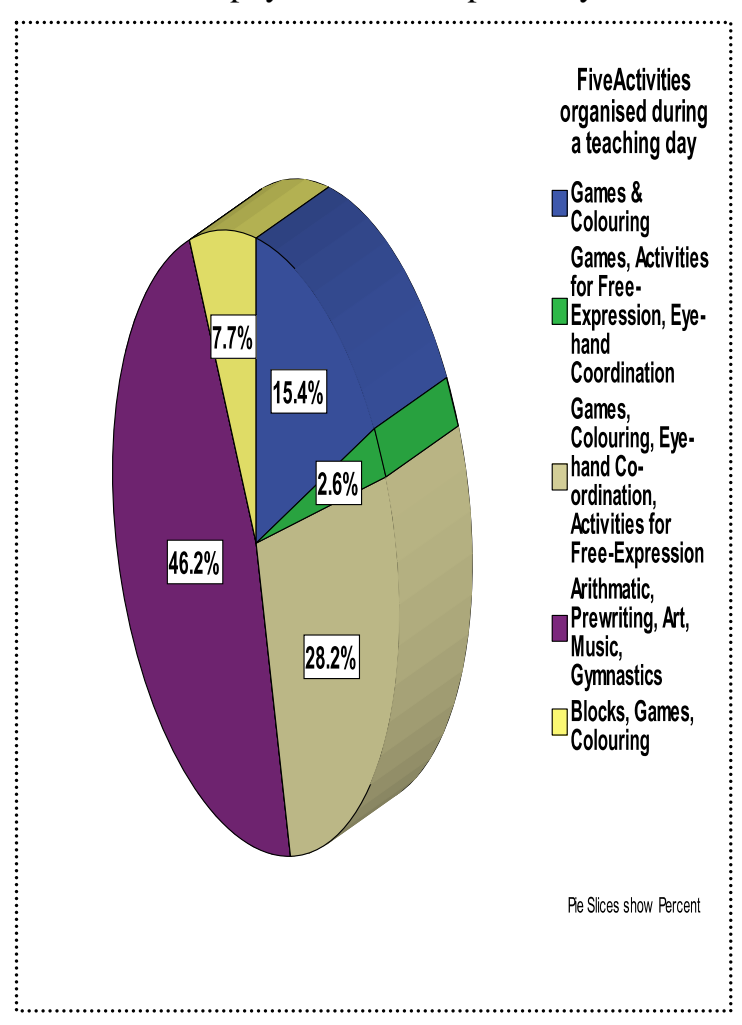

Figure 5. Activities Organised During Class

\subsection{Indoors and Outdoors Materials Used}

To understand whether a holistic development was taking place or not, it became necessary to explore the materials that were used by the ECE teachers in order to cater to all the domains of the young ones respectively. And it also became mandatory to find out what was provided, and how was that used in the ECE classrooms? So, the findings of the study established that consistent efforts were made to provide indoor materials for relevant activities almost every day. All the centres provided indoor materials like painting, clay, pictures, scissors, chart books, alphabets charts, building blocks, puzzles, toys, story books, logos, plaster seal, etc. It is worth noting here that the list of indoor materials too, perhaps, indicate that more emphasis was laid on development of motor skills. Although social, emotional and cognitive aspects were not neglected completely. The study also revealed that around $70 \%$ of them used outdoor materials every day on a regular basis. And the materials used were listed as Balls, Slides, Swings, Hoola Hoops, Seesaws, Climbing Rails and a few others. The emphasis was again more on physical 
development as compared to the other domains (Figure 6). However, none of them mentioned of any Nature Corner, or Pet's corner that could have catered to the development of emotional and social domains. In other words, both indoors as well as outdoors materials were primarily used to enhance physical domains. Nonetheless it should also be mentioned here that the teachers made an effort to select materials, both indoors as well as outdoor, and used them regularly. However, their inclination towards the enhancement of physical aspects could perhaps be due to the absence of a prescribed curriculum. The introduction of an ECE curriculum with appropriate guidelines could definitely overcome this problem, and could lead to an enhancement of an overall development instead!

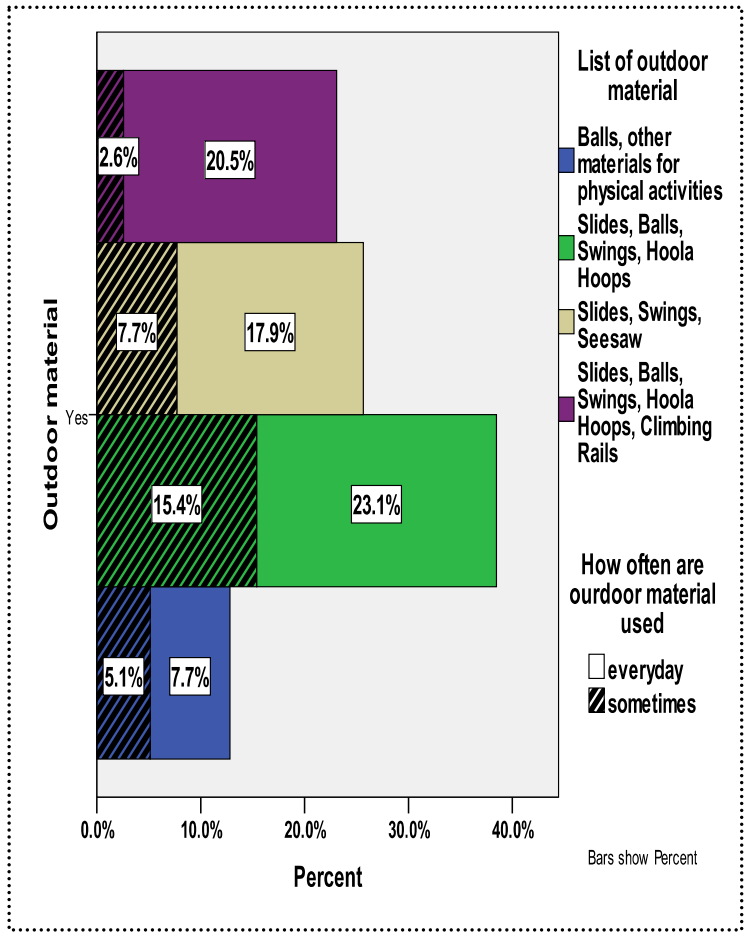

Figure 6. Outdoor Materials Used

\subsection{The issue of a Holistic Development}

In an ECE curriculum one expects a reflection of growth and learning in a holistic way that has interwoven emotional, social, cultural, physical and cognitive dimensions.

It is needless to say that an early childhood curriculum should recognise the central importance of emotions in a child's development. The development of emotional competence is an essential foundation for academic and social functioning. Curriculum goals, activities, teacherchild relationships need to be well planned. In an emotion-centred curriculum, children approach materials and activities with relish and are optimistic about their ability to figure out things and get help both from adults and other children whenever they need it. In such a programme, teachers create relationships that support emotional development of a child. Programmes that lack emotional focus may restrict individual and culturally compatible interests and styles. Planned activities can encourage children to talk, write and play about important issues that might build a strong link between affective and cognitive developments. Selection of emotionally relevant activities by ECE teacher might ensure children's sustained powerful explorations resulting in cognitive academic and emotional benefits [9]. Activities that help in emotional expressions, like music and creative art forms could well occupy a substantial amount of space in a well planned ECE curriculum.

Research shows that children prefer to work in cooperation with one another and prefer to get help from peers rather than teachers [12]; [15]. They show more turn taking behaviour which form attachments with others and show participation in educational and cooperative play activities. Thus, to enhance social development, a skillful teacher should be guided by a curriculum to select appropriate tasks that would serve as catalyst for social interaction and conversations and encourage their growth by pairing children or guiding conversation among the children about their common pursuit [3]. Not only that, they need to be guided that the best way to help children and to develop healthy lifestyle attitudes as was behaviors is to provide children with love and nurturing that builds strong, positive self-images based on attributes other than appearance e.g., kindness, trying hard, sharing, doing well in sports or school, etc. [16].

Similarly, physical development is vital during early childhood, as children continue to expand their repertoire of physical skills, adding to those that were mastered during infancy. During early years the finer and gross motor skills of children are developed and they become interested in performing well in activities like writing and arithmetic. So the ECE curriculum should provide guidelines for planning appropriate tasks that would help them in composing text without being distracted by poor motor coordination and letter formation [7].

Children not only grow physically during early childhood, but grow mentally as well. Children of this age continue to advance their skills in observing and interacting with the world around them. They also make tremendous leaps in how they process, store, and use information [16]. Development of their cognitive abilities take to new levels of richness and reflectivity and the resulting thoughtfulness allows for greater sophistication in the related areas of social relationships and selfdirected learning. Thus there is also a need to provide an appropriate ECE curriculum to the teachers that could guide them as how to provide cognitive development using appropriate curricular 
activities, and encourage children's involvement in creative play, mastery learning, problem solving and conversation in order to prepare them to face challenges and make them proficient in applying cognitive skills [3]. And the ECE teachers must provide opportunities for development of cognitive abilities to facilitate a bootstrapping of learning by development, and of development by learning [20].

Both the Rumbold Report Starting with Quality and the Royal Society of Arts Report Start Right emphasized a high-quality education in early years and stressed that the major prerequisites for a "highquality" education should be provision of an appropriate early learning curriculum [13]. They further recommended a curriculum based on eight main areas of learning: (1) aesthetic and creative, (2) human and social, (3) language and literacy, (4) mathematics, (5) physical, (6) science, (7) spiritual and moral, and (8) technology and said that these should be made available to all young children as it leads to lasting cognitive and social benefits in children. In other words, there is a need to provide an overall development that would guarantee the development of all the faculties of young children, in a holistic manner.

Unfortunately, the findings of the current study showed that about $54 \%$, of the respondents i.e. only half of the ECE centres, that took part in the study, provided the desired holistic development to the young children. On the contrary, almost half of them neither encouraged holistic development nor were they worried about neglecting some of the most important domains like cognitive, or social or emotional aspects in actual practice. In addition, majority of them, primarily, catered to the development of physical aspect as compared to the other domains in a platter! Which means, the quality of the ECE programmes that are running in Botswana are in question! This raises a concern, because the quality ECE programmes needs an adoption of a model of learning that weaves together patterns of linked experiences and meaning. This integrated view of learning sees the child's whole context, the physical development, the emotional stability; the relationships with others, the cognitive skills and the child's immediate needs at any moment that would affect and modify how a particular experience could contribute to the child's overall development. This view of learning sees the child as a person who wants to learn and sees the task as a meaningful whole [22].

\section{Conclusion}

Thus, it is needleless to say that efforts need to be made to provide an overall development to young children. And in order to that, the first move that we can take is to introduce an appropriate national ECE curriculum, that could at least provide guidelines both to pre-service as well as in-service ECE teachers regarding activities and materials that can enhance and interweave physical, social, emotional, as well as cognitive domains and thus provide a holistic development ensuring an overall enrichment and growth [5]. And in the mean time, certainly, we need to prepare the ECE teachers through workshops and seminars, especially the ones who are not formally trained in ECE, and provide useful guidelines regarding the strategies of offering rich and stimulating activities, while using appropriate indoors as well as outdoors materials. This would not only equip the ECE teachers with the desired skills and knowledge, but would also enable them enhancing the development of all the faculties of young children that leads to a holistic development. Giving emphasis to physical development is definitely is very important, but neglecting cognitive, social, as well as emotional aspects would be detrimental at such a tender age. As any lapse such as this during early childhood period, would definitely lead to an unbalanced developmental process, as we know that each one of these developmental aspects is very important in its own right. And a quality ECE programme is expected to provide them at tandem with well planned activities, using both indoors and outdoors materials.

\section{References}

[1] Ackerman. Debra J. (2005) Getting Teachers from Here to There: Examining Issues Related to an Early Care and Education Teacher Policy.Vol 7. No.1 Retrieved on 31/01/2007 from http://goliath.ecnext.com/coms2/gi_01994488250/Getting-teachers-from-here-to.html

[2] Alvestad, M. and Samuelsson, I. P. (1999). Early Childhood Research and Practice. A comparision of the national preschool curricula in Norway and Sweden ( $\mathrm{p} 1$ - 25). Vol 1: 1, no. 2 . http://www.ped.gu.se/users/pramling/early/curricul um.html. Retrieved on 18/08/06.

[3] Bose, K. (2005). Computer use in Reception schools, A Case of Gaborone, Botswana. Early Childhood Education Journal, 33(1)17-24.

[4] Bose, K., Monau, R, Masole, M. (2007). The Current Status of Early Childhood Care and Education (ECC\&E) Programs of Gaborone, Botswana (A Research Project Report submitted to the Office of Research and Development Unit). Gaborone, Botswana: University of Botswana.

[5] Bose, K. (2008). Gaps and remedies of early childhood care and education (ECCE) programs of Botswana. Educational Research and Reviews, 3(3), 77-82. http://www.academicjournals.org/ERR. ISSN 1996-0786 @ 2008 Academic Journals.

[6] Bredekamp, Sue, \& Copple, Carol (Eds.). (1997). Developmentally appropriate practice in early 
childhood programs (Rev. ed.). Washington, DC: National Association for the Education of Young Children.

[7] Davis, Bernadette Caruso and Shade, Daniel D. (1994). Integrate, Don't Isolate! Computers in the Early Childhood Curriculum-ERIC Digest 376991. Retrieved on Dec. 2003 from Website:http://www.kidsource.com/kidsource/cont ent2/integrate.computers.html.

[8] Essa, E.L.(2007). Introduction to early childhood education. Australia: Thompson Delmar Learning.

[9] Fleet, A. \& Patterson, C. (2001). Professional Growth Reconceptualized: Early Childhood Staff Searching for Meaning. (p 1 - 15) Vol 3 No.2, http://ecrp.uiuc.edu/v3n2/fleet.html. Retrieved on 18/08/06.

[10] Gay, L.R. and Airasian, P. (2003). Educational Research Competencies for Analysis and Applications. New Jersey: Merrill Prentice Hall.

[11] Hyson, Marylou. (2004). The emotional development of young children: Building an emotion centred curriculum. New York: Teachers College Press.

[12] King, J.A., \& N. Alloway. (1992). Preschooler's use of microcomputers and input devices. Journal of Educational Computing Research, 8, 451-68.

[13] Kwon, Young-Ihm. (2002). Changing Curriculum for Early Childhood Education in England. Early Childhood Research and Practice, 4 (2).

[14] Nastasi, B.K., \& Clements, D.H. (1993). Motivational and social outcomes of cooperative education environments. Journal of Computing in Childhood Education 4 (1): 15-43.

[15] Nastasi, B. K., \& Clements, D. H. (1994). Effectance motivation, perceived scholastic competence, and higher-order thinking in two cooperative computer environments. Journal of Educational Computing Research, 10(3), 249-275. EJ 486806.

[16] Oswalt, Angela. (2007). Early Childhood Cognitive Development: Introduction. Child Development and Parenting: Early Childhood. Retreived on 6th July from Website: http://www.mentalhelp.net/poc/view_doc.php?typ $\mathrm{e}=$ doc\&id $=12757 \& \mathrm{cn}=462$.

[17] Republic of Botswana (2001). Early Childhood Care and Education Policy - 2001. Botswana: Government Printers, Gaborone.

[18] Republic of Botswana. (2006). Botswana and UNESO-7th Edition. Botswana: Government Printers, Gaborone.

[19] Saluja, G. Early, D.M. Clifford, R. M. (2002). Early Childhood Research and Practice:
Demographic characteristics of Early Childhood teachers and structural element of Early Care in the United States. Vol. 4 No. 1. http://ecrp.uiuc.edu/v4n1/saluja.html. Retrieved on $18 / 08 / 2006$.

[20] Spodek, Bernard \& Saracho, Olivia, N. (2005), Handbook of Research on the Education of Young Children. USA; Routledge.

[21] Wiersam, W, Jurs, S. G. (2005). Research Methods in Education. Boston: Research Navigator.

[22] Wilson Henrica. (2005). Curriculum Document: Aapi'i Tamariki Potiki- Draft Notes. http://www.education.gov.ck/docs/curriculum/Cur riculum_ECE.pdf. Retreived on 6th July 2009. 